Cahiers $d u$ MONDE RUSSE

\section{Cahiers du monde russe}

Russie - Empire russe - Union soviétique et États indépendants

$55 / 3-4 \mid 2014$

Varia

\title{
Hiroaki Kuromiya, Conscience on Trial, The Fate of Fourteen Pacifists in Stalin's Ukaine, 1952-1953
}

\section{Alain Blum}

\section{OpenEdition}

\section{Journals}

Édition électronique

URL : http://journals.openedition.org/monderusse/8075

DOI : 10.4000/monderusse.8075

ISSN : $1777-5388$

\section{Éditeur}

Éditions de l'EHESS

\section{Édition imprimée}

Date de publication : 1 juillet 2014

Pagination : 419-421

ISBN : 978-2-7132-2441-6

ISSN : $1252-6576$

\section{Référence électronique}

Alain Blum, « Hiroaki Kuromiya, Conscience on Trial, The Fate of Fourteen Pacifists in Stalin's Ukaine, 1952-1953 », Cahiers du monde russe [En ligne], 55/3-4 | 2014, mis en ligne le 13 avril 2015, Consulté le 25 septembre 2020. URL : http://journals.openedition.org/monderusse/8075 ; DOI : https://doi.org/ 10.4000/monderusse.8075

Ce document a été généré automatiquement le 25 septembre 2020.

(c) École des hautes études en sciences sociales 


\title{
Hiroaki Kuromiya, Conscience on Trial, The Fate of Fourteen Pacifists in Stalin's Ukaine, 1952-1953
}

\author{
Alain Blum
}

\section{RÉFÉRENCE}

Hiroaki KUROMIYA, Conscience on Trial, The Fate of Fourteen Pacifists in Stalin's

Ukaine, 1952-1953, Toronto : University of Toronto Press, 2012, 212 p.

1 L'ouvrage d'Hiroaki Kuromiya traite d'un de ces nombreux procès de l'ère stalinienne tardive, qui a touché un ensemble de pauvres quasi illettrés résidant dans une même ville, Bila Tserkva, en Ukraine occidentale. Sont mis en cause quatorze chrétiens, qualifiés par la police d'" adventistes-réformistes ", faisant partie d'un groupe religieux issu de l'église adventiste du $7^{\mathrm{e}}$ jour. Hiroaki Kuromiya fonde son travail sur le dépouillement détaillé de l'ensemble $\mathrm{du}$ dossier pénal, constitué des actes d'arrestations, interrogatoires, jugements, condamnations, appels en révision et de la décision d'acquittement. L'auteur suit deux pistes. D'un côté, il cherche à définir ces personnes qui appartiennent à des mouvements religieux exprimant des formes de refus de la légalité soviétique; de l'autre, il s'intéresse aussi aux actions judiciaires et répressives qui jouent un rôle dans la transformation de ces personnages discrets et peu actifs socialement en groupes de conspirateurs. Le livre est construit autour d'une description précise des diverses étapes du procès. Par chapitres successifs, l'auteur nous rapporte les arrestations, la position des adventistes dans l'URSS stalinienne, les interrogatoires (deux chapitres), les témoignages et confrontations, le procès et, enfin, l'appel et l'acquittement en appel. L'auteur s'attache à faire parler les documents. Ainsi, le chapitre sur l'arrestation consiste en de courtes biographies, mais précises, de chacun des inculpés, sans ajout de commentaires superflus. Les interrogatoires sont résumés, inculpé après inculpé. Tout au long de l'ouvrage se dégage ainsi une forme de procès contre les engagements plus ou moins forts dans la foi, contre des attitudes 
perçues comme antisoviétiques, parfois affirmées non pas comme telles, mais à travers une défiance soutenue par la croyance que le pouvoir divin est supérieur au pouvoir soviétique, parfois fondées uniquement sur le refus de l'engagement dans l'armée.

Phénomène classique des procès staliniens, on voit aussi comment s'élabore la formation d'un groupe constitué, d'une secte, alors que pris individuellement, chacun des membres n'était que croyant. Les interrogatoires cherchent ainsi à dépasser la foi pour forger l'idée de groupe antisoviétique, d'organisation. Notons le cas intéressant d'un des inculpés qui reste muet durant tous les interrogatoires et le procès, mais parlera lors de la révision. Hiroaki Kuromiya émet l'hypothèse qu'il s'agit d'un agent, sans cependant disposer d'éléments de preuve.

3 L'ensemble de l'ouvrage reste au plus près des documents, dont il produit de nombreux extraits, replacés dans leur contexte, surtout celui de l'élaboration d'une culpabilité, qui tombera lors de l'appel, interjeté fin 1952 et débouté un mois à peine avant la mort de Stalin. En 1954, selon une procédure classique, le procureur général d'Union soviétique présentera un recours contre la décision de la Cour suprême d'Ukraine de rejet de l'appel. Une première réduction de peine est accordée. Les peines sont ensuite annulées, les unes après les autres, durant la période qui suit la loi d'amnistie de mars 1953, alors que les autorités soviétiques ne lèvent qu'avec lenteur, hésitation et incomplètement, les répressions politiques staliniennes.

Ce livre décrit donc dans le détail l'élaboration d'un procès, son développement et sa chute, à un moment charnière de l'histoire soviétique, autour d'une thématique essentielle, celle de la croyance et de la religion dans les milieux pauvres et illettrés. Cependant, il est regrettable que cet ouvrage soit conçu comme si aucune recherche n'avait encore été menée sur les procès. L'auteur affirme le caractère unique de son document. Sans doute a-t-il raison pour ce qui est de la question de la foi, mais on sait aussi à quel point, ces quinze dernières années, les questions soulevées par les mécanismes judiciaires et les procès staliniens ont suscité de travaux reprenant des problématiques comme celle de l'aveu, renouvelant nos questionnements, s'intéressant plus en détail à la production du discours, à la création de la culpabilité, etc.

Le choix fait par l'auteur de suivre pas à pas les étapes du parcours judiciaire plutôt que d'observer une approche thématique aboutit à la dispersion, sur l'ensemble de l'ouvrage, d'éléments de grand intérêt. L'étude aurait probablement gagné en profondeur si l'auteur avait procédé au regroupement thématique et à l'examen des dominantes qui se dégagent des différents interrogatoires. Certes, le choix chronologique est tout à fait pertinent mais il nous semble, dans ce cas, qu'un travail plus fouillé sur les déclarations des inculpés, fussent-elles passées par le filtre des enquêteurs, aurait permis de tendre vers la dimension attendue.

Enfin, on regrettera que la seconde ambition du livre - comprendre la nature de la foi des inculpés et leur place dans la société soviétique - ne bénéficie pas d'un traitement spécifique. Une analyse plus fine de la déportation, en 1952, des membres de certains groupes religieux de ces mêmes territoires ukrainiens, mais baltes aussi, aurait sans doute permis de mettre en évidence le lien qui unit le procès, objet de cet ouvrage, à la campagne générale de répression lancée contre plusieurs mouvements religieux et, aussi, de mieux appréhender les outils de la surveillance préalable des pratiquants, qui n'est pas étudiée ici. 
7 Cet ouvrage apparaît comme un nouvel épisode dans la compréhension des mécanismes d'exclusion qui traversèrent la société stalinienne, de l'usage des interrogatoires et du procès et du très lent effacement, qui ne fut jamais total, de ces processus, après la mort de Stalin. Il atteste à quel point les archives judiciaires conservent encore en leur sein des sources étonnantes et révélatrices de la société de l'époque.

\section{AUTEURS}

\section{ALAIN BLUM}

EHESS - CNRS - Centre d'études franco-russes, Moscou 